\title{
KIAA1199 Biomarker and Ultrasonographic Findings in Rheumatoid Arthritis Patients and their Correlation with Disease Activity
}

\author{
KIAA1199-Biomarker und ultrasonografische Befunde bei \\ Patienten mit rheumatoider Arthritis und Korrelation dieser \\ Ergebnisse mit der Krankheitsaktivität
}

Authors

Zahraa Ibrahim Selim¹, Eman H El-Hakeim², Eman Ahmed Hamed Omran³ ${ }^{3}$ Naglaa K. Idriss ${ }^{4}$, Marwa A. Gaber ${ }^{4}$, Sylvia V Ross ${ }^{5}$

Affiliations

1 Faculty of medicine Assuit university, rhematology and rehabilitation, Assuit, Egypt

2 Rheumatology and Rehablitation Department, Assiut, Assiut University Hospital, Egypt

3 Faculty of Medicine, Rheumatology, Rehabilitation and Physical Medicine, Assiut University, Assiut, Egypt

4 Medical Biochemictry, Assuit University, Assuit, Egypt

5 Rheumatology, Rehabilitation, Physical Medicine, Assuit university, Assuit, Egypt

Key words

KIAA1199, Power Doppler Ultrasound (PDUS), Rheumatoid Arthritis (RA)

Schlüsselwörter

KIAA1199, Power-Doppler-Ultraschall (PDUS),

Rheumatoide Arthritis (RA)

Bibliography

DOI https://doi.org/10.1055/a-0629-8340

Published online: 6.6.2018

Akt Rheumatol 2020; 45: 341-347

(c) Georg Thieme Verlag KG Stuttgart · New York ISSN 0341-051X

Correspondence

Dr. Eman H El-Hakeim

Rheumatology and Rehablitation Department

Assuit univeristy Hospitals

071515 Assiut

Egypt

Tel: + 20/106/1828 586, Fax: +20/884/14 060

emanelhakeim@yahoo.com

\section{ABSTRACT}

Introduction Rheumatoid arthritis (RA) is an autoimmune disease that affects multiple joints causing joint destruction. KIAA1199 is a novel angiogenic biomarker derived from fibroblast-like synoviocytes (FLS) it has a role in acceleration and proliferation of FLS and activation of angiogenic signaling pathways leading to erosion of cartilage and bone. Musculoskeletal ultrasound (MUSU) and Power Doppler (PDUS) directly visualizing the synovial membrane vessels, which is important in providing very early information on the changes in synovitis activity during the course of the inflammatory joint disease Objective To assess the serum level of angiogenic biomarker KIAA1199 in RA patients and its correlation with MSUS, PDUS findings, and the disease activity Patients and methods: Fifty RA patients and 40 healthy control persons age and sexmatched were recruited in this study, KIAA1199 was assessed in the serum of patients and controls, MSUS and PDUS were done for the wrist, elbow, and knee joints for all RA patients Results Serum KIAA1199 level was significantly higher among RA patients $4.36 \pm 1.22 \mathrm{ng} / \mathrm{dl}$ compared to control group $2.87 \pm 0.51 \mathrm{ng} / \mathrm{dl}(\mathrm{p}<0.001)$. There was a highly significant correlation between KIAA1199 level and DAS28 ( $p=0.004)$, and there was a significant correlation between the PDUS with KIAA1199 level and DAS28 ( $p=0.001,0.002$ respectively) in wrist joints

Conclusion KIAA1199 is a new pathway that enhancing cell proliferation and angiogenesis. Serum KIAA1199 level may be a useful biomarker for RA activity, and therapeutic target in RA. PDUS correlates significantly with clinical findings and novel angiogenic biomarker in RA patients.

\section{ZUSAMMENFASSUNG}

Einführung Die rheumatoide Arthritis (RA) ist eine Autoimmunerkrankung, die multiple Gelenke betrifft und eine Gelenkdestruktion verursacht. KIAA1199 ist ein neuer angiogenetischer Biomarker, der aus fibroblastenartigen Synoviozyten (FLS) gewonnen wird. Er spielt eine Rolle bei der Beschleuni- 
gung der Proliferation von FLS und der Aktivierung angiogenetischer Signalwege, die zur Erosion von Knorpel und Knochen führen. Muskuloskelettaler Ultraschall (MUSU) und Power-Doppler-Ultraschall (PDUS) ermöglichen eine direkte Darstellung der Gefäße in der Synovialmembran und liefern somit wichtige, sehr frühzeitige Informationen über Veränderungen der synovitischen Aktivität im Verlauf der entzündlichen Gelenkerkrankung.

Ziel Beurteilung des Serumspiegels des angiogenetischen Biomarkers KIAA1199 bei RA-Patienten und dessen Korrelation mit MSUS- und PDUS-Befunden und der Krankheitsaktivität.

Patienten und Methoden Beurteilung des Serumspiegels des angiogenetischen Biomarkers KIAA1199 bei RA-Patienten und dessen Korrelation mit MSUS- und PDUS-Befunden und der Krankheitsaktivität. Es wurden fünfzig RA-Patienten und 40 gesunde Kontrollprobanden entsprechenden Alters und Geschlechts in diese Studie aufgenommen. Bei den Patienten und den Kontrollprobanden wurde der Serumspiegel von KIAA1199 gemessen. Bei allen RA-Patienten wurden MSUS- und PDUS-Untersuchungen der Handgelenke, Ellbogen- und Kniegelenke durchgeführt.

Ergebnisse Der Serumspiegel von KIAA1199 war bei den RA-Patienten signifikant höher $(4,36 \pm 1,22 \mathrm{ng} / \mathrm{dl})$ als in der Kontrollgruppe $(2,87 \pm 0,51 \mathrm{ng} / \mathrm{dl})(\mathrm{p}<0,001)$. Es fanden sich eine hochsignifikante Korrelation zwischen dem KIAA1199Spiegel und dem DAS28 $(p=0,004)$ sowie eine signifikante Korrelation zwischen PDUS und KIAA1199-Spiegel bzw. PDUS und DAS28 ( $p=0,001$ bzw. 0,002) bei den Handgelenken.

Schlussfolgerung KIAA1199 ist ein neuer Biomarker für eine erhöhte Zellproliferation und Angiogenese. Der Serumspiegel von KIAA1199 kann die RA-Aktivität aufzeigen und als therapeutisches Ziel bei RA dienen. PDUS korreliert signifikant mit den klinischen Befunden und dem neuen angiogenetischen Biomarker bei RA-Patienten.

\section{Introduction}

Rheumatoid arthritis (RA) is an autoimmune, systemic inflammatory arthritis associated with both articular and extra-articular manifestations. The commonly affected joints are those of hands, wrists, and knees. While some of the rheumatoid patients have a mild self-limited disease, many suffer from joint destruction that can cause chronic pain, unsteadiness, deformity, disability and multiple co-morbidities [1].

Although the pathogenesis of RA is complex and is thought to be multifactorial, the interaction of pro-inflammatory mediators is a likely mechanism. The inflammation of the synovial lining of joints leads to its hyperplasia and influx of leukocytes and inflammatory cells [2,3]. This excessive migration of circulating leukocytes into the inflamed joint demands formation of new blood vessels to provide nutrients and oxygen to the hypertrophic joint. On this base, it is thought that one of the earliest histological observations in early RA is angiogenesis. [4, 5]. In addition, inflammatory associated angiogenesis, like in RA is now recognized as a key event in the formation and maintenance of the pannus, and without angiogenesis, leukocyte ingress could not occur $[6,7]$.

One of the identified angiogenic biomarkers are KIAA1199 (a 150-kDa protein). KIAA1199 expression was high in RA patients by fibroblast-like synoviocytes (FLS) derived from the lining layer of the synovial membrane. FLS are among the dominant cell types involved in pannus formation [8]. KIAA1199 with other angiogenic biomarkers may accelerate the proliferation of FLS cells and activate the downstream angiogenic signaling pathways, leading to the formation of the pannus, and erosion of the cartilage and bone in the progression of RA [9]. KIA1199 was first described as an inner ear-specific protein [10]. It was found to be accused of cancer progression, metastasis and poor prognosis of patients with cancer as determined in many clinical studies $[11,12]$.

Musculoskeletal ultrasound (MSUS) is found to be an ideal modality to detect subclinical joint inflammation and joint injury in patients with RA [13-15]. It is more sensitive than physical examination, and radiographic imaging. MSUS is also noninvasive and inexpensive in comparison to magnetic resonance imaging, and laboratory parameters $[13,16,17]$. In addition, MSUS Power Doppler (PD) imaging of synovitis has been suggested to reflect the pathology of synovial inflammation in patients with RA better than in grey scale imaging. So MSUS is a more sensitive reliable method for assessment of inflammatory activity $[13,18]$. As it directly visualizes the synovial-membrane vessels, which is important in providing very early information on the changes in synovitis activity during the course of inflammatory joint disease [19, 20].

The hypothesis of this study was that KIAA1199 biomarker could be used as a tool to detect the disease activity in RA patients, so the aim of our study is to assess the serum level of angiogenic biomarker KIAA1199 in RA patients and its correlation with MSUS, PDUS findings, and the disease activity.

\section{Patients and methods}

\section{Subjects}

Fifty patients fulfilling the 2010 ACR-EULAR classification criteria for RA [21] were recruited from the inpatients and outpatients' clinic of the Rheumatology, Rehabilitation and Physical Medicine Department of Assiut University hospitals, in the period from April 2016 to August 2017. Exclusion criteria comprised patients' refusal, patients aged less than 18 years old, a patient with other connective tissue diseases, chronic kidney and liver disease. Full history taking including age, sex, disease duration, and duration of morning stiffness, general and musculoskeletal examination were done to RA patients group.

The disease activity in RA patients was assessed by the 28 joint count Disease Activity Score (DAS 28) [22]. Modified health assessment questionnaire (mHAQ), patient global assessment, physician global assessment, clinical disease activity index (CDAI) performed to all patients.

Forty apparently healthy volunteers, age and sex-matched were also included as a control group. The protocol of the study supported by Ethical Committee for Scientific Research at Faculty of Medicine at Assiut University and informed written consents was taken from all patients. 


\section{Laboratory}

Eight $\mathrm{ml}$ of venous blood samples were collected from all subjects under complete aseptic condition by clean venipuncture then dispensed into three tubes: For rheumatoid factor (RF) and $\mathrm{C}$ reactive protein tests on the same day of blood collection, complete blood count, ESR measurement, and $3 \mathrm{ml}$ of collected blood in the plane tube were allowed to clot, centrifuged at 3,000 rpm for $20 \mathrm{~min}$ and plasma was then collected, aliquoted, and kept frozen at $-70^{\circ} \mathrm{C}$ until batch analysis.

\section{Enzyme-linked immunosorbent assay for human KIAA1199}

KIAA1199-level were detected in serum from patients with RA and controls. Standards and samples were incubated at room temperature in a micro ELISA plate coated with KIAA1199 monoclonal antibody (sc-164775, Santa Cruz, CA, USA). After incubation, washing, and addition of a specific detection antibody coupled to horseradish peroxidase, the substrate was added, and incubation was performed after the stop solution was added. The optical density was measured and different KIAA1199 concentrations were then determined.

\section{MSUS assessment of joints}

MSUS equipment used was General Electric (GE) LOGIQ 3 digital US scanner using a $7.5-10 \mathrm{MHz}$ transducer. Contact gel was applied to the skin to provide an acoustic interface. A detailed MSUS examination was done for wrists, elbows, and knees directly after blood sample collection. Both wrists were assessed in dorsal longitudinal radial and ulnar scans. Both elbows were assessed in the ventral longitudinal scan (humero-radial and humero ulnar) and dorsal longitudinal scan on olecranon fossa. Both knees were assessed in the suprapatellar longitudinal scan, medial and lateral longitudinal scans. The examined joints were evaluated systematically for the presence of synovial hypertrophy and Power Doppler signal. One Joint ultrasound findings were defined according to published OMERACT definitions [23]: A semi-quantitative scale for quantification of synovial thickening in B-mode MSUS was used, based on 4 point scales (0-3) as: Grade $0=$ absence of synovial thickening, Grade 1 = mild synovial hypertrophy, Grade 2 = moderate synovial hypertrophy, and Grade 3 = severe synovial hypertrophy.

PDUS: grade 0 = no flow in the synovium, 1 = single vessel signals, 2 = confluent vessel signals in less than half the area of the synovium, $3=$ vessel signals in more than half the area of the synovium.

To ensure a stringent definition of synovitis by ultrasound, only patients with synovial hypertrophy (SH) grade $\geq 2$ plus PDUS signal were classified as having active synovitis. If any assessed joint met these criteria, the patient was classified as having active synovitis.

We calculated the total signal score of Power Doppler (TSS) for all RA patients by summation of the PD signal score in six joints both elbows, wrists, and knees in all views.

\section{Statistical analysis}

Results were collected, tabulated, statistically analyzed by statistical package SPSS version 23. Two types of statistics were done; descriptive (e.g., no, percentage (\%), mean, standard deviation (SD) and range) and analytical one (student's t-test and Pearson's correlation analysis). The Student's t-test was to collectively indicate the presence of any significant difference between 2 groups for a normally distributed quantitative variable. Pearson's correlation analysis was used to show strength and direction of the association between 2 quantitative variables. P-value, was considered non-significant if $p>0.05$, significant difference if $p<0.05$, and highly significant if $p<0.01$.

\section{Results}

\section{Demographic characteristic of patients and control groups}

Fifty RA patients ( $90 \%$ females and $10 \%$ males) were compared with 40 healthy control persons ( $80 \%$ females and $20 \%$ males) included in this study ( $\mathrm{P}=0.198)$, with a range $\&$ mean of age \pm SD (18-63) 41.16 \pm 12.74 , (20-66) $40.08 \pm 12.21$ years respectively $(\mathrm{P}=0.968)$.

- Table 1 shows the clinical and laboratory data; the mean of disease duration was $7.43 \pm 0.87$ years, morning stiffness was $0.97 \pm 0.10 \mathrm{~h}$, and mean of the DAS- 28 score was $5.09 \pm 1.95$.

\section{Serum level of KIAA1199 and ROC curve}

Serum KIAA1199 level was significantly higher among RA patients $4.36 \pm 1.22 \mathrm{ng} / \mathrm{dl}$ compared to control group $2.87 \pm 0.51 \mathrm{ng} / \mathrm{dl}$

- Table 1 Clinical and laboratory data of patients group

\begin{tabular}{|c|c|}
\hline $\begin{array}{l}\text { Clinical and laboratory data in patients } \\
\text { group }\end{array}$ & Patient no $=\mathbf{5 0}$ \\
\hline Disease duration “years" (mean \pm SD) & $(0.25-30) 7.43 \pm 0.87$ \\
\hline Morning Stiffness “hours" (mean \pm SD) & $0.97 \pm 0.10$ \\
\hline Subcutaneous nodule (\%) & $7(14.0 \%)$ \\
\hline Pain (\%) & $43(86.0 \%)$ \\
\hline Swelling (\%) & $35(70.0 \%)$ \\
\hline Tender joint count "TJC" (mean \pm SD) & $8.28 \pm 1.07$ \\
\hline Swollen joint count "SJC" (mean \pm SD) & $5.00 \pm 0.70$ \\
\hline Visual analogue scale "VAS"(mean \pm SD) & $4.38 \pm 0.25$ \\
\hline Patient global assessment "PGA"(mean \pm SD) & $4.38 \pm 0.25$ \\
\hline Physician global assessment "Ph.GA" (mean \pm SD) & $3.56 \pm 0.29$ \\
\hline $\begin{array}{l}\text { Erythrocyte Sedimentation Rate "ESR"1 } 1 \text { st hour } \\
\text { “mm/h" (mean } \pm \text { SD) }\end{array}$ & $45.88 \pm 3.21$ \\
\hline $\mathrm{C}$ reactive protein “CRP” $\mathrm{mg} / \mathrm{L}($ mean $\pm \mathrm{SD})$ & $19.25 \pm 2.10$ \\
\hline Rheumatoid factor “RF"”IU/ml” (mean \pm SD) & $192.86 \pm 35.54$ \\
\hline Number of patient with positive RF(\%) & $40(80.0 \%)$ \\
\hline \multicolumn{2}{|l|}{ Complete Blood Count “CBC” } \\
\hline 1-Hb “g/dl” (mean $\pm S D)$ & $11.30 \pm 0.21$ \\
\hline 2-Platelets “ $\times 10^{3} \mathrm{uL}$ ” (mean \pm SD) & $317.90 \pm 11.09$ \\
\hline 4-WBCs “x106/uL” (mean \pm SD) & $6.45 \pm 0.28$ \\
\hline $\begin{array}{l}\text { Clinical disease activity index } \\
\text { "CDAl” (mean } \pm \text { SD) }\end{array}$ & $20.94 \pm 1.95$ \\
\hline DAS28 (disease activity score) (mean \pm SD) & $5.09 \pm 1.95$ \\
\hline $\operatorname{High}(\%)$ & $4(8.0 \%)$ \\
\hline Moderate(\%) & $21(42.0 \%)$ \\
\hline $\operatorname{Low}(\%)$ & $25(50.0 \%)$ \\
\hline
\end{tabular}


- Table 2 KIAA1199 serum level in patients \& control groups.

\begin{tabular}{|l|l|l|l|}
\hline Item & $\begin{array}{c}\text { Patients } \\
\text { group } \\
\mathbf{n = 5 0}\end{array}$ & $\begin{array}{c}\text { Control } \\
\text { group } \\
\mathbf{n}=\mathbf{4 0}\end{array}$ & P-value \\
\hline $\begin{array}{l}\text { KIAA1199 in ng/ } \\
\text { dl (mean } \pm \text { SD) }\end{array}$ & $4.36 \pm 1.22$ & $2.87 \pm 0.51$ & $\mathrm{P}<0.000^{* * *}$ \\
\hline
\end{tabular}

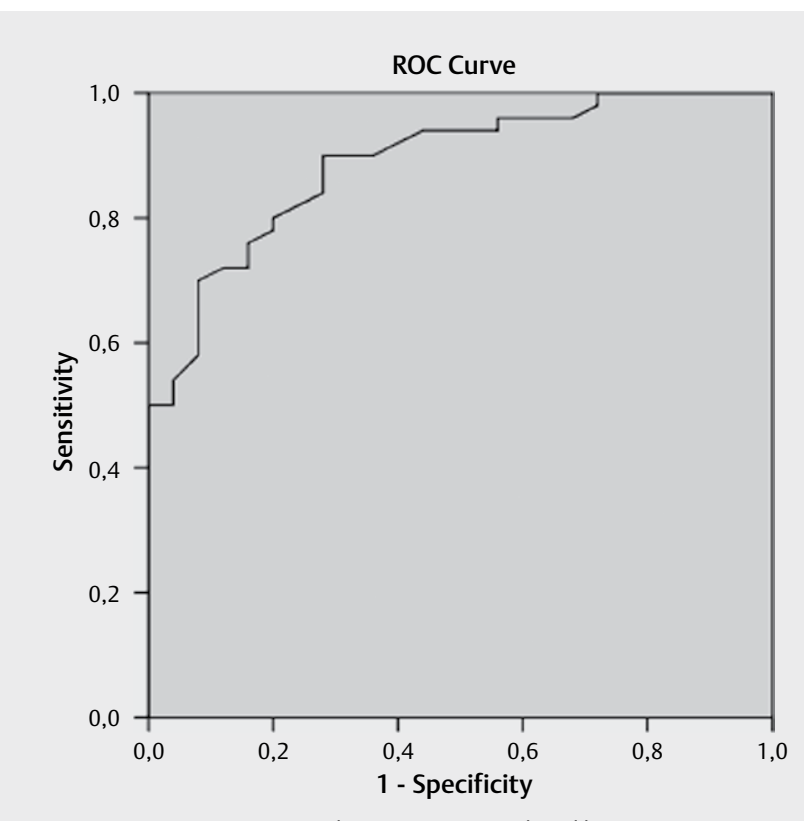

Diagonal segments are produced by ties.

- Fig. 1 shows the ROC curve analysis of KIAA1199 in serum of RA patients. The area under the curve $(A \cup C=0.888)$ for RA. A cutoff value of $3.55 \mathrm{ng} / \mathrm{dl}$ detected in RA patients at the sensitivity of $70.0 \%$ and the specificity of $99.02 \%$.

$(p<0.001)$. ( $>$ Table 2$)$. With the aim of verifying the diagnostic role of KIAA1199 in RA, we conducted a receiver operator characteristic (ROC) curve analysis of KIAA1199. Our result indicates that the areas under the ROC curve for the serum KIAA1199 level from RA patients were 0.89 indicating good diagnostic value (80-90\%). Cutoff values corresponding to $3.55 \mathrm{ng} / \mathrm{dl}$ were able to detect active RA with a sensitivity of $70 \%$ and specificity of $90.02 \%$ ( $\mathbf{F i g . ~ 1 ) . ~}$

- Table 3: shows the correlation between serum level of KIAA1199 and history, clinical, laboratory data, and assessment of the disease activity. There was a highly significant correlation between serum level of KIAA1199 and morning stiffness, ESR, CDAI, CRP, DAS28, and mHAQ ( $p=0.004,0.009,0.002,0.000,0.004,0.007$ respectively), and a significant correlation with $\mathrm{RF}, \mathrm{Hb}$, and platelets ( $p=0.019,0.032,0.035$ respectively), with no correlation with age, disease duration.

\section{Correlation between KIAA1199, PD, and disease activity}

The correlation between serum KIAA1199 level and DAS 28 with PDUS finding and synovial thickness score, for different joints
- Table 3 Correlation between serum KIAA1199 level with clinical, laboratory data, and assessment of disease activity in patients group.

\begin{tabular}{|c|c|c|}
\hline \multirow[t]{2}{*}{ Clinical \&laboratory data } & \multicolumn{2}{|c|}{ KIAA1199 } \\
\hline & $\mathbf{r}$ & $\mathbf{p}$ \\
\hline Age & $0.129-$ & 0.371 \\
\hline Diseases duration & 0.025 & 0.865 \\
\hline MS & 0.121 & $0.004 * *$ \\
\hline TJC & 0.505 & $0.004 * *$ \\
\hline SJC & 0.798 & $0.001^{* *}$ \\
\hline VAS & 0.733 & $0.000 * *$ \\
\hline ph.GA & 0.716 & $0.001^{* *}$ \\
\hline ESR & 0.341 & $0.009 * *$ \\
\hline CRP & 0.114 & $0.002^{* *}$ \\
\hline RF & 0.037 & $0.019^{*}$ \\
\hline $\mathrm{Hb}$ & -0.578 & $0.032 *$ \\
\hline Platelets. & 0.299 & $0.035^{*}$ \\
\hline WBCs & 0.226 & 0.123 \\
\hline CDAI & 0.793 & $0.000 * *$ \\
\hline DAS28 & 0.67 & $0.004^{* *}$ \\
\hline mHAQ & 0.094 & $0.007^{* *}$ \\
\hline \multicolumn{3}{|c|}{$\begin{array}{l}{ }^{*} \text { Correlation is significant at the } 0.05 \text { level }\left(2 \text {-tailed); }{ }^{*} \text { Correlation }\right. \\
\text { is highly significant at the } 0.01 \text { level }(2 \text {-tailed); MS = Morning } \\
\text { stiffness, TJC= tender joint count, SJC= swollen joint count,, } \\
\text { VAS =Visual, Ph G A= physician global assessment, analogue } \\
\text { scale,,Hb = hemoglobin, ESR = erythrocyte sedimentation rate, } \\
C R P=C \text { - reactive protein,, RF = Rheumatoid factor, WBCs = white } \\
\text { blood cells, CDAI = clinical disease activity index, DAS28 = Disease } \\
\text { activity score, mHAQ = modified Health Assessment Questionnaire }\end{array}$} \\
\hline
\end{tabular}

among RA patients, is shown in $>$ Table 4. There was a significant positive correlation between MSUS (SH) with serum level of KIAA1199 and DAS28 ( $p=0.001,0.004$ respectively), and also between the PDUS with serum level of KIAA1199 and DAS28 $(p=0.001,0.002$ respectively) in wrist joints only, while there was no positive correlation between both elbow and knee joints. There was a positive correlation between TSS and DAS28 ESR, CDAI, mHAQ $(p<0.001)$ and serum level of KIAA1199 $p<0.05$ among RA group shown in $>$ Table 5 .

\section{Discussion}

As a basic mechanism in any inflammatory arthritis like RA, leukocytes migrate from the bloodstream through the vessel wall into the synovium, which may also contain a number of cell adhesion molecules, as integrin, selectins and their respective ligands $[5,24,25]$. This excessive migration of circulating leukocytes into the inflamed joint demands formation of new blood vessels to provide nutrients and oxygen to the hypertrophic joint. In addition, these inflammatory mediators including pro-inflammatory cytokines and chemokines may promote both endothelial cells adhesion, receptor expression and hence angiogenesis. Moreover, some 
- Table 4 Correlation between serum KIAA1199 level and DAS28 ESR with Synovial hypertrophy "SH" and power Doppler signal 'PD' among patients group.

\begin{tabular}{|c|c|c|c|}
\hline $\begin{array}{l}\text { Synovial hypertro- } \\
\text { phy }\end{array}$ & & KIAA1199 & DAS28 ESR \\
\hline \multirow[t]{2}{*}{ Wrist SH } & $r$ & 0.556 & 0.733 \\
\hline & $\mathrm{P}$ & $0.001^{* *}$ & $0.004^{* *}$ \\
\hline \multirow[t]{2}{*}{ Elbow SH } & $\mathrm{R}$ & -0.075 & 0.251 \\
\hline & $\mathrm{P}$ & 0.583 & 0.554 \\
\hline \multirow[t]{2}{*}{ Knee SH } & $\mathrm{R}$ & $-0.033-$ & 0.217 \\
\hline & $\mathrm{P}$ & 0.720 & 0.251 \\
\hline \multicolumn{4}{|c|}{ Power Doppler signal (PD) } \\
\hline \multirow[t]{2}{*}{ Wrist PD } & $\mathrm{R}$ & 0.656 & 0.493 \\
\hline & $\mathrm{P}$ & $0.001^{* *}$ & $0.002 * *$ \\
\hline \multirow[t]{2}{*}{ Elbow PD } & $\mathrm{R}$ & 0.085 & 0.027 \\
\hline & $\mathrm{P}$ & 0.091 & 0.132 \\
\hline \multirow[t]{2}{*}{ Knee PD } & $\mathrm{R}$ & $-0.033-$ & 0.217 \\
\hline & $\mathrm{P}$ & 0.720 & 0.251 \\
\hline \multicolumn{4}{|c|}{$\begin{array}{l}{ }^{*} \text { Correlation is significant at the } 0.05 \text { level }\left(2 \text {-tailed); }{ }^{*} \text { Correlation }\right. \\
\text { is highly significant at the } 0.01 \text { level }(2 \text {-tailed); } \mathrm{SH}=\text { Synovial } \\
\text { hypertrophy, PD = power Doppler signal }\end{array}$} \\
\hline
\end{tabular}

- Table 5 Correlation between total signal score with serum KIAA 1199 level, DAS 28-ESR, CDAI, m HAQ:.

\begin{tabular}{|l|l|l|}
\hline \begin{tabular}{l} 
Total signal score (TSS) \\
\hline KIAA1199
\end{tabular} & $\mathbf{r}=\mathbf{P}=$ \\
\hline DAS-28 ESR & 0.037 & $0.04^{*}$ \\
\hline CDAI & 0.468 & $0.001^{* *}$ \\
\hline mHAQ & 0.462 & $0.001^{* *}$ \\
\hline
\end{tabular}

adhesion molecules themselves induce neovascularization $[25,26]$. One of the most evident signs of synovitis is the increase in synovial vascularization due to angiogenesis, which is crucial for synovial growth and invasiveness $[27,28]$.

In our study, we clarified a significant increase in the serum level of KIAA1199 in patients with RA, vs. controls. This is compatible with the results of a previous study by Yang et al. 2015 as they found a significant increase in the expression of KIAA1199 in plasma, synovial tissue, and synovial fluid in RA patients in comparison to healthy controls [11]. Also, Wang et al. 2012 designed a comparative proteomics study of proteins in primary cultures of RA and normal synoviocytes. They concluded that all angiogenesis-related proteins were up-regulated in the synovial tissue of patients with
RA and this may be the essential cause of pannus formation. They also elucidated increase expression of KIAA1199 by 5.19 fold in RA synoviocytes in comparison to healthy controls, which may be one of the factors that lead to the development of vasculature in the synovial membrane of patients with RA [10]. Another study by Yoshida et al. 2013 showed that KIAA1199 is involved in hyaluronan (HA) degradation in normal skin fibroblasts and arthritic synovial fibroblasts, which is independent of CD44 and HYAL enzymes. Their findings provide that KIAA1199 is implicated in physiological and pathological HA catabolism and suggest that therapeutic interventions targeting KIAA1199 may be of clinical value. Collectively, these data suggesting that increased level of KIAA1199 might play an important role in the pathogenesis of RA by different pathways [29].

In this study, KIAA1199 ROC curve analysis showed that the $A U C=0.888$ for RA patients with a sensitivity of $70.0 \%$ and the specificity of $99.02 \%$. In the study of Yang and his colleagues; 2015 [11] they found that the sensitivity of KIAA1199 biomarker by analysis of ROC curve in plasma, synovial, and synovial tissue of RA patient was $72 \%, 84 \%$ and $80 \%$ respectively and specificity was $80 \%$, $93.3 \%$ and $93.3 \%$ respectively. Our results indicate that KIAA1199 may be a potential diagnostic biomarker of RA disease activity.

We noticed that the serum KIAA1199 levels were significantly correlated with morning stiffness, ESR, RF, Hb, CDAI, CRP, DAS28, platelets, and mHAQ, with no correlation with age, disease duration, and WBCs. This is in accordance with Yang et al., who demonstrate a positive correlation between KIAA1199 and DAS28. These data indicate that the level of KIAA1199 is not only increased in RA but also an index that correlated closely with clinical parameters of RA disease activity [11].

In the current study, we found that there was a positive correlation between serum KIAA1199 level, and SH \&PD in wrist joint but not in elbow and knee joints. This can be explained by that the wrist joint is the most commonly affected joint in RA for swelling and tenderness [30]. Serum KIAA1199 level was also correlated with TSS. This confirms the role of serum KIAA1199 level in synovitis and angiogenesis associated with RA. These results are in accordance with studies that found a positive correlation between MSUS finding and levels of Angiopiotein-2, and VEGF. [31]. Kelly et al. 2015 demonstrated that there is a relationship between PD signal and angiogenic gene expression, they also found a correlation between $\mathrm{SH}$ and cellular markers of synovial inflammation and pro-inflammatory cytokines [32]. In another study, they demonstrated that there was a positive correlation between PDUS scores with disease activity, and with plasma biomarkers such as VEGF, Matrix metalloproteinases-3, and tissue inhibitor of metalloproteinases-1. All these biomarkers have a role in the budding of endothelial cells and which is an early step in angiogenesis [33]. The TSS was highly positively correlated with DAS28, CDAI, and $\mathrm{MHAQ}$ in agreement with Naredo et al. 2008 and Dougados et al. 2010 studies [34, 35].

In this study, PDUS has been regarded as an important tool for globally examining the degree of synovitis in RA. PDUS signal was assessed in 6 joints for each patient, other studies used different numbers of joints $[35,36]$. It is difficult to determine the minimal numbers of joints to be included in a global US score. There was a lack of a clear definition of synovitis as well as varying validity data with respect to the proposed scores. So, scoring systems comprise 
a wide range and number of joints. More studies are needed in order to achieve optimal US scoring systems for monitoring patients with RA in clinical trials and in clinical practice [23, 35].

PDUS correlates significantly with disease activity and novel angiogenesis biomarker along with synovial histopathology in patients with RA. Unlike clinical examination, PDUS has the ability to discover subclinical synovitis making it a more reliable, sensitive to change, and convenient investigational method. Therefore, it should have a potential role in standard monitoring and follow-up of patients for response to treatment as well as prediction of future structural damage [36-38]. The MSUS has some limitations because its technique is operator dependent, not every rheumatologist is skilled in its use and assessments are time consuming if large number of joints are examined.

\section{Conclusion}

Serum KIAA1199 level may be a useful angiogenic biomarker to detect RA disease activity, and seems to be a potential therapeutic target in RA. Also, PDUS has the ability to detect subclinical synovitis not easily detected by clinical examination and correlate with serum KIAA1199 biomarker in our study.

\section{Funding}

No external funding, the study was done and covered by institutional resources.

\section{Conflict of interest}

The authors declare that they have no conflict of interest.

\section{References}

[1] Houri LE, Watad A, Whitby A et al. Coexistence of Ischemic Heart Disease and Rheumatoid Arthritis Patients - a Case Control Study. Autoimmun Rev. 2016; 15: 393-396

[2] Szekanecz Z, Szegedi G, Koch AE. Angiogenesis in rheumatoid arthritis: Pathogenic and clinical significance. J Invest Med 1998; 46: 27-41

[3] Koch AE. Review: Angiogenesis: Implications for rheumatoid arthritis. Arthritis Rheum 1998; 41: 951-962

[4] Walsh DA. Angiogenesis and arthritis. Rheumatology 1999; 38: 103-112

[5] Hayes AJ. Angioneogenesis in rheumatoid arthritis. Lancet 1999; 354 : 423-424

[6] Szekanecz Z, Koch AE. Mechanism of disease: Angiogenesis in inflammatory diseases. Nat Clin Pract Rheumatol 2007; 3: 635-643

[7] Veale D, Fearon U. Inhibition of angiogenic pathways in rheumatoid arthritis: Potential for therapeutic targeting. BestPract Res Clin Rheumatol 2006; 20: 941-947

[8] Wang JG, Xu WD, Zhai WT et al. Disorders in angiogenesis and redox pathways are main factors contributing to the progression of rheumatoid arthritis: A comparative proteomics study. Arthritis Rheum 2012; 64: 993-1004
[9] Yang X, Qiu P, Chen B et al. KIAA1199 as a potential diagnostic biomarker of rheumatoid arthritis related to angiogenesis. Arthritis Res Ther 2015; 17: 140

[10] Abe S, Usami S, Nakamura Y. Mutations in the gene encoding KIAA1199 protein, an inner-ear protein expressed in Deiters' cells and the fibrocytes, as the cause of non-syndromic hearing loss. J Hum Genet 2003; 48: 564-570

[11] Matsuzaki S, Tanaka F, Mimori K et al. Clinicopathologic significance of KIAA1199 overexpression in human gastric cancer. Ann Surg. Oncol 2009; 16: 2042-2051

[12] Tiwari A, Schneider M, Fiorino A et al. Early insights into the function of KIAA1199, a markedly overexpressed protein in human colorectal tumors. PLoS One 2013; 8: e69473

[13] Naredo E, Bonilla G, Gamero F et al. Assessment of inflammatory activity in rheumatoid arthritis: A comparative study of clinical evaluation with grey scale and power Doppler ultrasonography. Ann Rheum Dis 2005; 64: 375-381

[14] Joshua F, Edmonds J, Lassere M. Power Doppler ultrasound in musculoskeletal disease: a systematic review. Semin Arthritis Rheum 2006; 36: 9910-9918

[15] Brown AK, Conaghan PG, Karim Z et al. An explanation for the apparent dissociation between clinical remission and continued structural deterioration in rheumatoid arthritis. Arthritis Rheum 2008; 58: 2958-2967

[16] Szkudlarek M, Court-Payen M, Stranberg C et al. Power Doppler ultrasonography for assessment of synovitis in the metacarpophalangeal joints of patients with rheumatoid arthritis: A comparison with dynamic magnetic resonance imaging. Arthritis Rheum 2001; 44: 2018-2023

[17] Terslev L, Torp-Pedersen S, Savnik A et al. Doppler ultrasound and magnetic resonance imaging of synovial inflammation of the hand in rheumatoid arthritis: a comparative study. Arthritis Rheum 2003; 48: 2434-2441

[18] Saleem B, Brown AK, Quinn M et al. Can flare be predicted in DMARD treated RA patients in remission, and is it important? A cohort study. Ann Rheum Dis 2012; 71: 1316-1321

[19] Vreju FL, Ciurea M, Rosu A et al. Power Doppler sonography, a non-invasive method of assessment of the synovial inflammation in patients with early rheumatoid arthritis. Rom J Morphol Embryol 2011; 52: 637-643

[20] Foltz V, Gandjbakhch F, Etchepare F et al. Power Doppler ultrasound, but not low-field magnetic resonance imaging, predicts relapse and radiographic disease progression in rheumatoid arthritis patients with low levels of disease activity. Arthritis Rheum 2012; 64: 67-76

[21] Aletaha D, Neogi T, Silman AJ et al. Rheumatoid arthritis classification criteria: an American College of Rheumatology/ European League Against Rheumatism collaborative initiative. Ann. Rheum Dis 2010 69: 1580-1588

[22] Wolfe F. Which HAQ is best? A comparison of the HAQ, MHAQ and RA-HAQ, a difficult 8 item HAQ (DHAQ), and a rescored 20 item HAQ (HAQ20): Analyses in 2,491 rheumatoid arthritis patients following leflunomide initiation. J Rheumato 2001; 28: 982-989

[23] Mandl P, Naredo EWakefield et al. OMERACT Ultrasound Task Force. A systematic literature review analysis of ultrasound joint count and scoring systems to assess synovitis in rheumatoid arthritis according to the OMERACT filter. J Rheumatol 2011; 38: 2055-2062

[24] Szekanecz Z, Koch AE. Vascular involvement in rheumatic diseases: 'vascular rheumatology'. Arthritis Res Ther 2008; 10: 224

[25] Agarwal SK, Brenner MB. Role of adhesion molecules in synovial inflammation. Curr Opin Rheumatol 2006; 18: 268-276 
[26] Szekanecz Z, Koch AE. Macrophages and their products in rheumatoid arthritis. Curr Opin Rheumatol 2007; 19: 289-295

[27] Szekanecz Z, BesenyeiT Paragh G et al. Angiogenesis in rheumatoid arthritis. Autoimmunity 2009; 42: 563-573

[28] Lee $S$, Chen TT, Barber CL et al. Autocrine VEGF signaling is required for vascular homeostasis. Cell 2007; 130: 691-703

[29] Yoshida H, Nagaoka A, Kusaka-Kikushima A et al. KIAA1199, a deafness gene of unknown function, is a new hyaluronan binding protein involved in hyaluronan depolymerization. Proc Natl Acad Sci USA 2013; 110: 5612-5617

[30] Terao C, Hashimoto M, Yamamoto K et al. Three Groups in the 28 Joints for Rheumatoid Arthritis Synovitis - Analysis Using More than 17,000 Assessments in the KURAMA Database. PLoS ONE 2013; 8: e59341 10. 1371

[31] Vreju Fl, Ciurea M, Rosu A et al. Power Doppler sonography, a non-invasive method of assessment of the synovial inflammation in patients with early rheumatoid arthritis. Rom J Morphol Embryol 2011; 52: 637-643

[32] Kelly S, Bombardieri M, Humby F et al. Angiogenic gene expression and vascular density are reflected in ultrasonographic features of synovitis in early Rheumatoid Arthritis: an observational study. Arthritis Res Ther 2015; 17: 58
[33] Kawashiri SY, Kawakami A, Iwamoto $\mathrm{N}$ et al. The powerDoppler ultrasonography score from 24 synovial sites or 6 simplified synovial sites, including the metacarpophalangeal joints, reflects the clinical disease activity and level of plasma biomarkers in patients with rheumatoid arthritis. Rheumatology 2011; 50: 962-965

[34] Naredo E, Rodríguez M, Campos C et al. Validity, reproducibility, and responsiveness of a twelve-joint simplified power Doppler ultrasonographic assessment of joint inflammation in rheumatoid arthritis. Arthritis Rheum 2008; 59: 515-522

[35] Dougados M, Jousse-Joulin S, Mistretta F et al. Evaluation of several ultrasonography scoring systems for synovitis and comparison to clinical examination: results from a prospective multicenter study of rheumatoid arthritis. Ann Rheum Dis 2010; 69: 828-833

[36] Bhasin S, Cheung P. The Role of Power Doppler Ultrasonography as Disease Activity Marker in Rheumatoid Arthritis. Disease Markers www.Hindawi.com 2015 ID 325909, 9 pages

[37] Ohrndorf S, Backhaus M. Pro musculoskeletal ultrasonography in rheumatoid arthritis. Clin Exp Rheumatol 2015; 33: S50-S53

[38] Mandl P, Kurucz R, Niedermayer D et al. Contributions of ultrasound beyond clinical data in assessing inflammatory disease activity in rheumatoid arthritis: current insights and future prospects. Rheumatology (Oxford) 2014; 53: 2136-2142 